\title{
Efecto Antimicrobiano del Jugo de Chile Jalapeño (Capsicum annuum var. annuum) en Queso Sopero
}

\author{
Pedro de Jesús Sánchez-López, \\ Egresado de Ingeniería en Alimentos, División Académica Multidisciplinaria \\ de los Ríos, Universidad Juárez Autónoma de Tabasco, México
}

Francisco Rodríguez-Flores,

Técnico Académico de Ingeniería en Alimentos.

División Académica Multidisciplinaria de los Ríos,

Universidad Juárez Autónoma de Tabasco, México

Nicolás González-Cortés,

Ana Laura Luna-Jiménez,

Román Jiménez-Vera,

Miembro del Cuerpo Académico Desarrollo Sustentable.

División Académica Multidisciplinaria de los Ríos,

Universidad Juárez Autónoma de Tabasco, México

Doi:10.19044/esj.2019.v15n33p238 URL:http://dx.doi.org/10.19044/esj.2019.v15n33p238

\section{Resumen}

Los antimicrobianos son aditivos alimentarios importantes en la conservación de alimentos. El objetivo de este trabajo fue evaluar el efecto del jugo de chile jalapeño en la calidad mcirobiológica de queso crema tropical. $\mathrm{Se}$ evaluaron cuatro tratamientos mediante un diseño experimental completamente al azar de un factor, con cuatro niveles de jugo $(0,20,30$ y 40 $\%$ ), tres repeticiones y tres variables de respuestas (coliformes totales, levaduras y Staphylococcus aureus) mantenidos durante dos días a temperatura ambiente $\left(22-28^{\circ} \mathrm{C}\right)$. No se encontró diferencia significativa entre las concentraciones de 20 y $30 \%$ con el tratamiento control, mientras que el efecto inhibitorio de la concentración de $40 \%$ contra S. aureus y levaduras fue estadísticamente significativo $(\mathrm{p}<0.05)$. Sin embargo, aunque se logró disminuir la concentración de estos microorganismos, no se alcanzó la concentración permitida por la norma oficial mexicana. El jugo de chile jalapeño puede ser un conservador natural que ayude a disminuir el deterioro de productos de buena calidad microbiológica, apoyando su vida de anaquel.

Palabras clave: Inhibición, Chile, Patógenos, Lácteo, Queso 


\title{
Antimicrobial Effect of Jalapeño Pepper Juice (Capsicum annuum var. annuum) on Sopero Cheese
}

\author{
Pedro de Jesús Sánchez-López, \\ Egresado de Ingeniería en Alimentos, División Académica Multidisciplinaria \\ de los Ríos, Universidad Juárez Autónoma de Tabasco, México
}

Francisco Rodríguez-Flores,

Técnico Académico de Ingeniería en Alimentos.

División Académica Multidisciplinaria de los Ríos,

Universidad Juárez Autónoma de Tabasco, México

Nicolás González-Cortés,

Ana Laura Luna-Jiménez,

Román Jiménez-Vera,

Miembro del Cuerpo Académico Desarrollo Sustentable.

División Académica Multidisciplinaria de los Ríos,

Universidad Juárez Autónoma de Tabasco, México

\begin{abstract}
Antimicrobials are important food additives in food preservation. The objective of this work was to evaluate the effect of jalapeño chili juice on the microbiological quality of tropical cream cheese. Four treatments were evaluated by a completely randomized one-factor experimental design, with four juice levels $(0,20,30$ and 40\%), three repetitions and three response variables (total coliforms, yeasts and Staphylococcus aureus) maintained for two days at room temperature $\left(22-28^{\circ} \mathrm{C}\right)$. No significant difference was found between the concentrations of 20 and $30 \%$ with the control treatment, while the inhibitory effect of the concentration of $40 \%$ against $\mathrm{S}$. aureus and yeasts was statistically significant $(\mathrm{p}<0.05)$. However, although the concentration of these microorganisms was reduced, the concentration allowed by the official Mexican standard was not reached. Jalapeño chili juice can be a natural preservative that helps reduce the deterioration of products of good microbiological quality, supporting your shelf life.
\end{abstract}

Keywords: Inhibition, Pepper, Pathogens, Dairy, Cheese 


\section{Introducción}

Se calcula que alrededor del $20 \%$ de los alimentos producidos en el mundo se pierden por acción de los microorganismos (Rodríguez, 2011). Las frutas, verduras carnes, pescado, mariscos, cereales, leguminosas, grasas, aceites, leche y agua utilizados en la industria alimentaria son susceptibles de contaminación microbiana, la cual ocasiona alteraciones y deterioro en sus propiedades físicas, químicas y biológicas que pueden afectar la eficiencia de los procesos y la comercialización de productos alimenticios (Robles \& Chalini, 2017).

Por otra parte, los alimentos alterados pueden resultar perjudiciales para la salud de los consumidores (Rodríguez, 2011). En los países industrializados se estima que el $30 \%$ de la población sufre de una enfermedad transmitida por alimentos al año y, a nivel mundial, 2.2 millones de personas mueren a causa de enfermedades diarreicas. La industria alimentaria necesita reducir o eliminar los agentes patógenos y alterantes de los alimentos que pueden afectar la salud de los consumidores (Pastrana-Puche, De Paula \& Gallo-García, 2017).

Ante este panorama, los antimicrobianos se encuentran entre los aditivos alimentarios más importantes; el uso de antimicrobianos en alimentos es una práctica común en la industria alimenticia, con la finalidad de conservarlos con las características adecuadas para su consumo. Por muchos años se han utilizado antimicrobianos sintetizados químicamente. Sin embargo, en algunos casos se ha reportado que estas sustancias han causado daño en la salud de los consumidores, lo que ha ocasionado el rechazo de la población a los alimentos procesados (Rodríguez, 2011).

Aunque la mayor parte de los conservadores usados en alimentos son de origen químico, existen diversos productos de origen natural provenientes de plantas que pueden ser usados en la conservación de alimentos. A nivel mundial, se estima que del $1 \%$ al $10 \%$ de las especies de plantas son usadas como alimento. En la actualidad, está aumentando el interés por los antimicrobianos de origen natural, con la finalidad de ser utilizados para prolongar la vida útil de los alimentos y la seguridad para el consumidor (Rodríguez, 2011).

Los chiles se utilizan en muchas regiones del mundo como acompañamiento de los alimentos, ya que proporcionan un sabor acre y aroma. Además de su uso alimentario, los chiles se han empleado por sus propiedades antibacterianas y antifúngicas; se están realizando investigaciones para determinar su potencial para la aplicación de extractos de chile en la industria alimentaria en lugar de conservadores artificiales. A medida que surjan nuevos patógenos resistentes a los antibióticos transmitidos por los alimentos, el descubrimiento de antimicrobianos naturales en los chiles será invaluable para 
la ciencia de los alimentos (Omolo, Wong, Mergen, Hastings, Le, Reiland, Case, \& Baumler, 2014).

Las investigaciones de Cerón-Carrillo, Munguía-Pérez, García y Santiesteban-López (2014) relacionaron la actividad antimicrobiana de tres especies de chile: poblano (Capsicum annuum var annuum), habanero (Capsicum chinense) y serrano (Capsicum annuum L. Acuminatum) en relación a tres microrganismos: Escherichia coli, Lactobacillus casei y Penicillium spp. Se encontró que el extracto de chile habanero presentó el mayor efecto inhibitorio para los microorganismos evaluados, lo cual se relacionó con un péptido presente en las semillas de esta especie de chile que presenta efecto antimicrobiano, así como con el contenido los compuestos capsaicinoides.

De igual manera, Acero-Ortega, Dorantes-Álvarez, Jaramillo-Flores, Hernández-Sánchez y López-Malo (2003) evaluaron extractos de los chiles habanero, serrano y pimiento por el efecto de sus compuestos antimicrobianos naturales en el crecimiento de la bacteria fitopatógena Erwinia carotovora subsp. carotovora. Los extractos de las tres variedades de chile y algunos de sus constituyentes como los ácidos metacumárico y transcinámico inhibieron el crecimiento del microorganismo. La capsaicina y la dihidrocapsaicina no afectaron el crecimiento de la bacteria.

Bacon, Boyer, Denbow, O’Keefe, Neilson y Williams (2016) investigaron la actividad antimicrobiana de los frutos de Capsicum annuum. La fracción que inhibió el crecimiento de Listeria monocytogenes contenía compuestos pertenecientes a un grupo de compuestos específicos de $C$. annuum conocidos como capsianósidos. A su vez, Cerón, Santiesteban- López y Acle (2016) analizaron las concentraciones inhibitorias de la mezcla de extractos alcohólicos de chile serrano y habanero contra Escherichia coli y Listeria monocytogenes. Se encontró que el chile habanero tuvo el menor efecto inhibitorio contra $E$. coli y L. monocytoegenes. Se observó un mayor efecto antimicrobiano cuando se combinan los extractos que cuando se aplican individualmente.

Por su parte, Sandhya y Vijayakumar (2016) identificación la actividad antimicrobiana de amplio espectro de ocho especies de Capsicum contra dos patógenos humanos Staphylococcus aureus y Streptococcus mutante. Los extractos etanólicos de Capsicum annuum var. glabriusculum, Capsicum sp. var. pimienta larga y delgada de Cayena y Capsicum sp. chile violeta de Kandhari fueron quienes mostraron una alta inhibición para los dos patógenos en comparación con las otras especies de Capsicum.

Por otra parte, las enfermedades transmitidas por alimentos son un grave problema de salud pública en el mundo. Entre las causas más frecuentes se encuentran los patógenos bacterianos, los cuales generan desde síntomas gastrointestinales hasta complicaciones que pueden conducir a la muerte. En 
un estudio realizado por Soto, Pérez y Estrada (2016) identificaron cinco microorganismos patógenos implicados en enfermedades de transmisión alimentaria: Salmonella spp., Listeria monocytogenes, Escherichia coli, Aeromonas spp. y Vibrio spp, aunque la mayor incidencia correspondió al género Salmonella.

Otro de los patógenos involucrados en enfermedades transmisibles por alimentos reportado por Guzmán, Rodríguez-Rodríguez y Calderón-Rangel (2017) es el Staphylococcus aureus, productor de enterotoxinas. Este patógeno es capaz de producir diarrea, vómito y deshidratación. Con la finalidad de ofrecer nuevos antimicrobianos capaces de controlar el crecimiento de bacterias patógenas en alimentos, el objetivo de este trabajo fue evaluar in vitro el efecto del jugo de chile jalapeño sobre el crecimiento de bacterias de interés alimentario.

\section{Materiales y Métodos}

Se evaluó el efecto del jugo de chile jalapeño sobre el crecimiento de la microbiota de queso crema tropical fresco, con la finalidad de emplear el chile jalapeño en la conservación de productos lácteos.

Jugo de chile jalapeño. Se utilizaron chiles jalapeños (Capsicum annuиm var. annuum) de primera calidad de acuerdo a la clasificación de la NMX-FF-025-SCFI-2007, adquiridos en un supermercado local. De este lote se seleccionaron chiles con un grado de madurez de acuerdo a la clasificación de Sáenz y D’Alolio (2007), color verde uniforme, tamaño homogéneo y ausencia de daños físicos aparentes. Los frutos seleccionados se lavaron con agua potable y con ayuda de un extractor se separó el jugo de la fibra. El jugo fue filtrado empleando papel filtro Whatman número $10 \mathrm{y}$ centrifugado a 3,000 rpm durante 5 min para eliminar impurezas. Se mantuvo en refrigeración hasta el momento de ser utilizado.

Queso sopero. Se utilizó queso sopero artesanal (San Antonio®) también conocido como queso crema tropical elaborado en Tenosique, Tabasco, México, con leche entera de vaca no pasteurizada, en presentación de $250 \mathrm{~g}$. El queso sopero se considera un queso fresco, de acuerdo a su grado de maduración: frescos (seis días), semi-madurados (40 días) y madurados (> de 70 días) (Ramírez-López \& Vélez-Ruiz, 2012; Villegas, Santos \& Cervantes, 2016). El queso crema tropical se produce en áreas restringidas del país y se comercializa localmente en zonas con una temperatura media mensual que oscila entre 22 y $28^{\circ} \mathrm{C}$ (Barba-Macías, Rangel-Mendoza \& Ramos-Reyes, 2006; Manjarrez, Hernández, De Jong, Nahed, De Dios \& Salvatierra, 2007).

Tratamientos. Para cada tratamiento se utilizaron $100 \mathrm{~g}$ de queso fresco adicionados con 0, 20, 30 y $40 \mathrm{ml}$ de jugo de chile filtrado y centrifugado, almacenados en bolsas Ziploc®. Se homogenizaron 
manualmente y se mantuvieron a temperatura ambiente (media mensual entre 22 y $28^{\circ} \mathrm{C}$ ), durante el tiempo del experimento (48 h), para evaluar el efecto del jugo en el crecimiento microbiano de manera acelerada.

Cuantificación de microorganismos. La concentración de grupos bacterianos se cuantificó por el método de cultivo en superficie (Corona \& Jiménez, 2004): coliformes totales (Agar de Bilis y Rojo Violeta, BD Bioxon, cat. 214300), levaduras (Agar Papa Dextrosa, BD Bioxon, cat. 211900) y Staphylococcus aureus (Agar de Sal y Manitol, Bioxon®) incubados a $37^{\circ} \mathrm{C}$ durante $24 \mathrm{~h}$.

Análisis estadístico. Se evaluaron cuatro tratamientos mediante un diseño experimental completamente al azar de un factor, con cuatro niveles ( 0 , 20, 30 y $40 \%$ de jugo de chile), tres repeticiones y tres variables de respuestas: concentración (Log UFC/g) de coliformes totales, levaduras y Staphylococcus aureus), después de dos días de almacenamiento a temperatura ambiente. Los datos fueron comparados mediante un Análisis de Varianza de un factor con un alfa de $0.05 \mathrm{y}$, los promedios analizados mediante una comparación múltiple de medias de Tukey.

\section{Resultados y discusión}

En este trabajo se evaluó el efecto del jugo de chile jalapeño, a diferentes concentraciones, sobre el crecimiento de microorganismos de interés alimentario en queso sopero mantenido a temperatura ambiente. Se utilizó queso fresco con una calidad microbiológica inicial de coliformes totales $(\log 4.37 \pm 0.43 \mathrm{UFC} / g)$, Staphylococcus aureus $(\log 4.88 \pm 0.14$ $\mathrm{UFC} / \mathrm{g}$ ) y levaduras (Log $4.78 \pm 0.61 \mathrm{UFC} / \mathrm{g})$. De acuerdo con la norma oficial mexicana NOM-121-SSA1-1994, en quesos frescos se acepta hasta Log 2.00 $\mathrm{NMP} / \mathrm{g}$ de coliformes fecales, Log 3.00 UFC/g de $S$. aureus y Log $2.70 \mathrm{UFC/g}$ de levaduras, lo que indica que los valores microbiológicos indicadores del queso sopero se encuentran por arriba de los valores permitidos por la norma oficial mexicana.

El efecto del jugo de chile jalapeño en la concentración de microorganismos indicadores del queso se relacionó con el porcentaje de jugo adicionado. Desde el punto de vista de los factores analizados, los resultados obtenidos con las concentraciones de 20 y $30 \%$ no mostraron efecto en la concentración de los microorganismos, sin mostrar diferencia significativa entre ellos, mientras que la concentración de $40 \%$ fue estadísticamente diferente con las anteriores $(p<0.05)$.

En cuanto a los microrganismos indicadores, se analizó la diferencia entre su concentración inicial y final; se encontró un efecto inhibitorio en el crecimiento de $S$. aureus y levaduras mientras que, en los coliformes totales, la concentración final fue superior a la inicial, en todas las concentraciones de jugo evaluadas. 
La Figura 1 muestra la tendencia obtenida en los coliformes totales donde se observa una correlación positiva entre el porcentaje de jugo y la concentración de microorganismos; estos resultados pueden relacionarse con lo hallazgos reportados por Omolo et al. (2014), quienes determinaron que la capsaicina en concentraciones de 0.20 a $0.30 \mathrm{mg} / \mathrm{ml}$ afecta el crecimiento de E. coli, actuando como bacteriostático que, aunque no produce la muerte de la bacteria, impide su reproducción. En chiles jalapeños se han reportado valores de capsaicina desde $0.091 \mathrm{mg} / \mathrm{ml}$ en chiles verdes hasta $1.52 \mathrm{mg} / \mathrm{ml}$ en chiles maduros (Mendoza, 2013). En este experimento, se utilizaron chiles jalapeños verdes, por lo que el nivel esperado de capsaicina pudo ser bajo y no producir un alto efecto bacteriostático.

Lo anterior indica que el jugo de chile puede ser efectivo como conservador en productos con una calidad microbiológica dentro de los parámetros permitidos por las normas. De igual manera, se esperaría que en especies del género Capsicum con mayores concentraciones de capsaicina, como los frutos de pimientos rojos oleorresina con porcentajes de capsaicina alrededor de $60 \mathrm{mg} / \mathrm{g}$ (Abdullah, Badjah, Abdelaty \& Abdel, 2011) puedan producir un mejor efecto bacteriostático en la conservación de alimentos frescos.

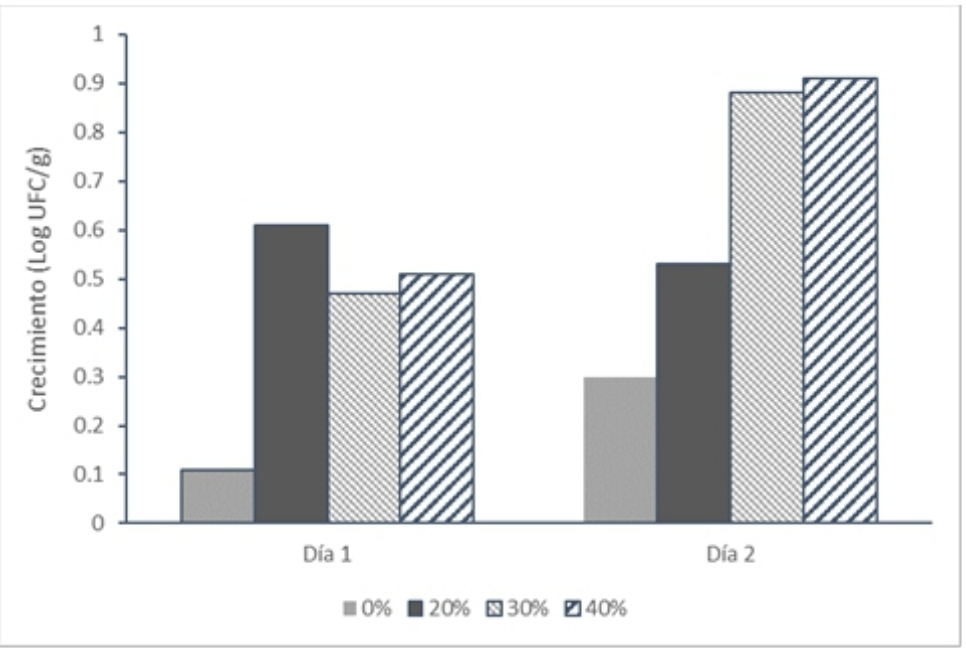

Figura 1. Efecto del jugo de chile jalapeño en coliformes totales en queso crema tropical

También es importante analizar las características de los microorganismos como los coliformes; estudios que sugieren que la susceptibilidad de cepas microbianas a extractos vegetales se relaciona con la condición de Gram negativas o positivas de los microorganismos. Aunque no se obtuvieron datos concluyentes, García y Herrera (2007) evaluaron extractos de Allium cepa en cinco cepas bacterianas donde Salmonella spp. resultó la 
más resistente frente a la acción de los extractos empleados, mientras que $S$. aureus demostró ser la cepa más susceptible, lo que sugiere la posibilidad de una menor susceptibilidad de las cepas Gram negativas, como las bacterias coliformes.

Por otra parte, también es importante analizar el tipo de solvente utilizado para realizar los extractos; en este estudio, se decidió emplear jugo de chile jalapeño, sin emplear solventes, para no alterar el sabor del queso crema tropical empleado en el experimento. Sin embargo, en un estudio realizado por Colivet, Belloso y Hurtado (2006) mostraron que los extractos con una mayor inhibición del crecimiento microbiano fueron los etanólicos. Estos resultados probablemente están relacionados con la solubilidad de los componentes activos presentes en los frutos de Capsicum sp. en etanol. Entre los componentes activos se encuentra el ácido clorogénico, soluble principalmente en alcohol etílico e insoluble en otros solventes $y$, las cumarinas, sustancias solubles en soluciones acuosas de hidróxido de sodio, etanol y metanol.

De igual manera, el alcohol etílico es el solvente que puede extraer los compuestos presentes en los frutos del género Capsicum, ya que el agua sólo es capaz de extraer sustancias con las cuales puede hacer puentes de hidrógeno y, los éteres, extraen sustancias apolares. El alcohol, en cambio, puede extraer sustancias parcialmente hidrófobas que puedan tener actividad bactericida (Colivet et al., 2006). En otro estudio, Bacon et al. (2016) encontró una mayor inhibición bacteriana de los extractos creados con metanol y etanol que el agua caliente.

Otro factor que pudo influir en los resultados inhibitorios obtenidos con el chile jalapeño de este estudio fue el proceso previo dado a los chiles; en este experimento, la extracción del jugo de chile se realizó a temperatura ambiente, entre 22 y $28^{\circ} \mathrm{C}$. En reportes presentados por Colivet et al. (2006) los extractos se obtuvieron de chiles verdes secados a $100{ }^{\circ} \mathrm{C}$, con los que se obtuvo un efecto inhibidor mayor para Escherichia coli que los secados a 70 ${ }^{\circ} \mathrm{C}$. Estos investigadores plantean que las temperaturas entre 60 y $70{ }^{\circ} \mathrm{C}$ son favorables para las degradaciones enzimáticas y entre 25 a $30{ }^{\circ} \mathrm{C}$ preferible para la conservación de los principios activos o emplear una temperatura por arriba de 100 a $120{ }^{\circ} \mathrm{C}$. En este último caso los fenómenos enzimáticos se detienen, lo que se conoce como estabilización.

Otro factor que afecta la inhibición microbiana de los extractos de chiles está relacionado con la especie del chile y la porción evaluada. En estudios realizados por Hleba, Petrová, Kordiak, Kántor, Čuboň, Kluz, Shariati y Kačániová (2015) reportaron la actividad antibacteriana de las salsas de chile habanero contra bacterias patógenas seleccionadas, como Escherichia coli, Bacillus thuringiensis, Yersinia enterocolitica y Salmonella enterica subsp. Typhimurium. Estos investigadores reportaron que la mayor actividad 
antibacteriana de la salsa de chile se observó en contra de Salmonella enterica subsp. Typhimurium (33\%), seguida contra Yersinia enterocolitica $(16.65 \%)$. También las salsas de chile tienen un efecto antibacteriano más débil contra Escherichia coli y Bacillus thuringiensis. Estos datos confirman que es posible emplear el chile jalapeño como una estrategia de innovación de sabor en quesos artesanales y obtener una acción en la inhibición de microorganismos patógenos de alimentos.

Además, Cerón et al. (2016) analizaron las concentraciones inhibitorias de la mezcla de los extractos de chile serrano y habanero contra Escherichia coli y Listeria monocytogenes. La fruta del chile habanero demostró tener el mayor contenido de capsaicinoides. Se observó que la fruta completa del chile habanero y las semillas del mismo tienen el menor efecto inhibitorio contra E. coli y L. monocytoegenes, respectivamente. Se observó también efectos sinérgicos y aditivos cuando se combinaban los extractos en contra de ambas bacterias.

Otro factor importante que interviene en la inhibición microbiológica de los extractos de chile es la composición del extracto, ya que además de los compuestos capsinoides, pueden interferir la presencia de otros componentes. Omolo et al., (2014) evaluaron un extracto de chile habanero donde la concentración de capsaicina y capsaicinoides utilizada no mostró un efecto inhibitorio sobre L. monocytogenes, siendo que el chile habanero contiene el mayor contenido de capsaicina. Sin embargo, un extracto de pimiento morrón, que contiene ácido m-cumumérico y ácido cinámico, pero no capsaicina, mostró un buen efecto inhibidor sobre dicha bacteria.

Además de los coliformes totales como indicadores microbiológicos en alimentos, es importante analizar el efecto del jugo de chile jalapeño en la concentración de Staphylococcus aureus debido a su importancia clínica y epidemiológica relacionada con las altas tasas de morbilidad y mortalidad, así como con los costos de atención hospitalaria (Cervantes-García, GarcíaGonzález \& Salazar-Schettino, 2014). En el caso de S. aureus, a diferencia de los coliformes, el efecto del jugo de chile jalapeño mostró una inhibición en la concentración inicial y final; se observó una correlación positiva en la inhibición con la mayor concentración del jugo (40 \%). La Figura 2 muestra la tendencia obtenida en el crecimiento de este microorganismo.

Por otra parte, la resistencia bacteriana a los agentes antimicrobianos se ha convertido en un problema de salud cada vez más grave en los últimos años. Entre las estrategias mediante las cuales se puede disminuir la resistencia microbiana, es la sobreexpresión de las bombas de flujo de salida como NorA de $S$. aureus, que conduce a una concentración subletal del agente antibacteriano en el sitio activo que a su vez puede predisponer al organismo al desarrollo de un objetivo de alto nivel a base de resistencia (Felicetti, 
Cannalire, Burali, Massari, Manfroni, Barreca, Tabarrini, Schindler, Sabatini, Kaatz \& Cecchetti, 2017).

Para S. aureus, Omolo et al. (2014) reportaron la posibilidad que la capsaicina actúe como un inhibidor de la bomba de flujo de salida NorA de $S$. aureus. La concentración inhibitoria mínima de ciprofloxacina se ha visto reducida de 2 a 4 veces en presencia de capsaicina. La reducción fue más prominente para $S$. aureus SA-1199B (sobreproductor de NorA) en comparación con $S$. aureus SA-1199 (tipo salvaje) hasta $25 \mathrm{mg} / \mathrm{l}$ de capsaicina. La cepa $S$. aureus SA-K1758 (NorA nulo) no mostró reducción en la concentración inhibitoria mínima de ciprofloxacina.

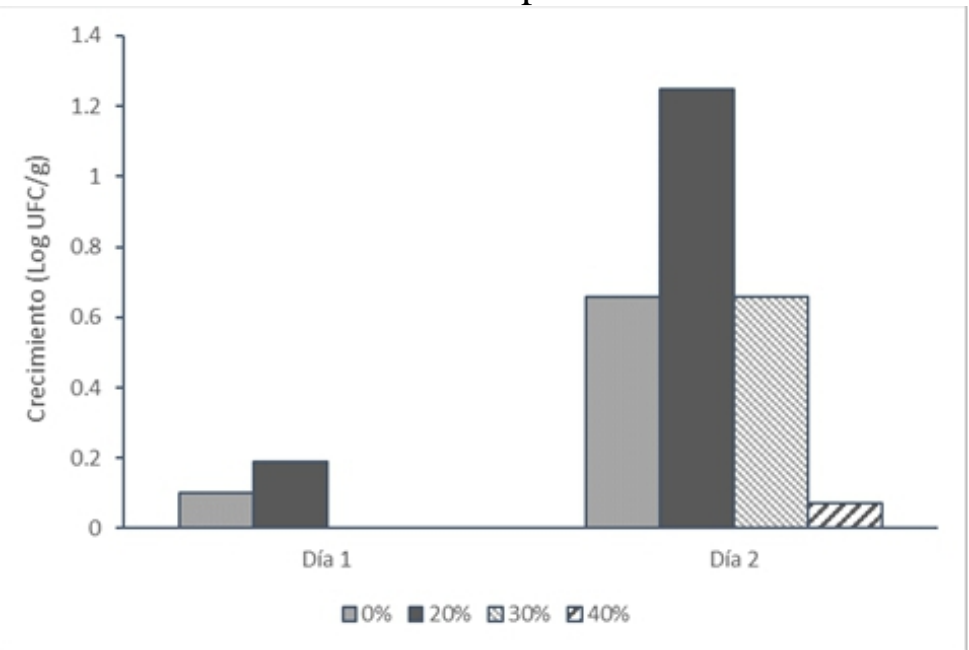

Figura 2. Efecto del jugo de chile jalapeño sobre $S$. aureus en queso

El solvente también afecta la inhibición del crecimiento de $S$. aureus. Los investigadores Koffi-Nevry, Clément, Yesse, Koussémon y Yao (2012) evaluaron el efecto de extractos de metanol y acuosos de Capsicum annuum y Capsicum frutescens sobre $S$. aureus, Se encontró que ambos extractos son efectivos contra $S$. aureus, sin embargo, los extractos de metanol mostraron el mayor efecto. El agua es un extractor débil de compuestos activos con actividades antimicrobianas. Los frutos de Capsicum pueden ser una fuente de agentes bactericidas naturales para ser utilizados en alimentos y sistemas medicinales (Ameya, Aklilu, Bisrat, Nassir \& Negash, 2018).

Las levaduras son otro grupo indicador de gran valor en los alimentos, ya que están presentes en distintas variedades de quesos, frecuentemente en alto número. Estos organismos podrían contribuir de manera significativa al proceso de maduración de estos productos o, por el contrario, podrían producir alteraciones en ellos (Cardozo, Fusco \& Carrasco, 2018). La Figura 3 muestra los efectos del jugo de chile jalapeño en la inhibición del crecimiento de este grupo indicador en una matriz proteica, como el queso crema tropical. Al igual que para $S$. aureus, se encontró un efecto inhibitorio proporcional al 
incremento de la concentración de jugo, presentando una mayor inhibición con la mayor concentración de jugo $(40 \%)$.

El mecanismo por el cual, los chiles afectan el crecimiento celular de las levaduras se relaciona con la capsaicina. En estudios realizados por Kurita, Kitagawa, Kim, Momose y Iwahashi (2002) en levaduras, analizaron el mecanismo antimicrobiano de la capsaicina y encontraron que induce un elemento de estrés osmótico, lo que reprime los genes clave para la biosíntesis de la membrana, los componentes ribosómicos y el crecimiento celular. Las características de crecimiento de las cepas sugieren que el gen PDR5 es importante para la resistencia a la capsaicina. Las investigaciones sugieren que la capsaicina ingresa a las células y funciona como una sustancia tóxica para las células de levadura.

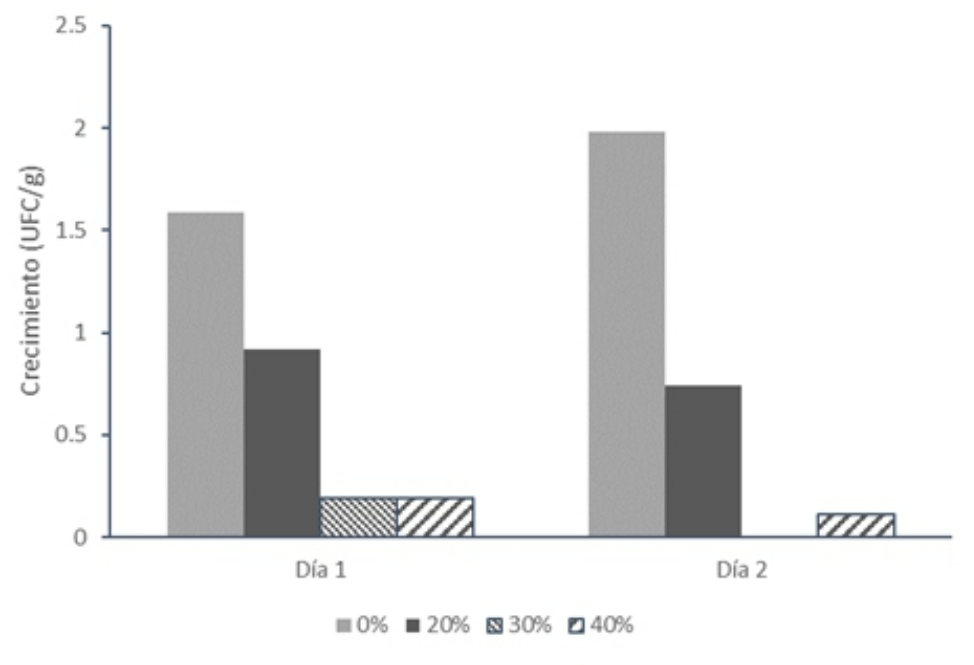

Figura 3. Efecto del jugo de chile jalapeño sobre levaduras en queso.

Los productos de elaboración artesanal como los quesos representan uno de los derivados lácteos con mayor aceptación, no obstante, estos productos no cuentan con registros que suministren un análisis de la calidad y las condiciones de comercialización. Los investigadores Rodríguez, Borras, Pulido \& Garcia (2015) evaluaron la carga bacteriana de queso fresco artesanal del mercado de Tunja, Colombia. Se efectuaron recuentos de coliformes totales y mesófilos aerobios, encontrando conteos superiores a la norma establecida para los microorganismos evaluados. Recuentos tan marcados evidencian una deficiente calidad sanitaria en los productos comercializados.

Por su parte, Vásquez, Salhuana, Jiménez y Abanto (2018) analizaron muestras de empresas productoras de queso fresco industrial en Cajamarca, Perú. Se realizaron los análisis microbiológicos pertinentes para la determinación de mesófilos, coliformes, Escherichia coli, Salmonella spp. y S. aureus. Estos resultados fueron comparados con la Norma Sanitaria que 
establece los criterios microbiológicos de calidad sanitaria e inocuidad para los alimentos y bebidas de consumo humano (R.M. N 591-2008-MINSA). La carga microbiana promedio de todas las muestras de queso fresco industrial superó los límites establecidos por la norma sanitaria. De igual manera, Romero-Castillo, Leyva-Ruelas, Cruz-Castillo y Santos-Moreno (2009) evaluaron muestras de queso crema tropical, de cinco queserías en Tonalá, México y encontraron que los quesos no cumplieron con las normas microbiológicas para bacterias coliformes fecales, E. coli y Salmonella sp.

En quesos artesanales de Corrientes, Argentina, Cardozo et al. (2018) evaluaron la presencia de levaduras en las materias primas y en la cuajada con la que se elabora este queso. Los recuentos de levaduras fueron del orden de $10^{3}$ a $10^{7} \mathrm{UFCl}$ g. En leche se observó un amplio predominio del género Candida, la incidencia de otros géneros fue poco significativa. En el agente coagulante también predominó netamente el género Candida, seguido por los géneros Myxozyma y Debaryomyces. Los aislamientos obtenidos de los quesos correspondieron a los mismos géneros que fueron predominantes en el agente coagulante, con el mismo orden de prevalencia.

La contaminación microbiana de alimentos es un problema serio para la industria alimentaria por las grandes pérdidas económicas que trae consigo. Este fenómeno es mixto por la participación de bacterias, hongos y levaduras. Aunque el papel de las levaduras es secundario en la contaminación microbiana de alimentos, las condiciones ambientales de preservación de estos, que tienden a inhibir el crecimiento de bacterias, han favorecido la aparición de levaduras contaminantes, causantes igualmente de afectaciones en los parámetros organolépticos de buena calidad en alimentos frescos, semielaborados y elaborados (Orberá, 2004).

En esta era de resistencia a los antibióticos y la aparición de mutantes microbianos patógenos, es de gran importancia tener conocimientos sobre los compuestos antimicrobianos secundarios, aparte de los antibióticos conocidos actualmente. En un aspecto diferente, se puede establecer una relación genética entre eucariotas y procariotas que responden a la capsaicina debido a un gen receptor común (Agarwal, Das, Dias \& Shanbhag, 2017).

En relación a la calidad microbiológica de los alimentos, el empleo del chile en la alimentación es parte de las tradiciones gastronómicas en muchos países, pero al mismo tiempo, es un ingrediente alimentario con el potencial de disminuir la concentración de microorganismos patógenos. En quesos, sobre todo artesanales, los niveles de microorganismos indicadores suelen ser altos, lo que constituye un riesgo para la población consumidora. El empleo de chile en quesos permitirá innovar en el sabor, así como mejorar la calidad microbiológica. 


\section{Conclusión}

Se evaluó el efecto antimicrobiano de tres concentraciones de jugo de chile jalapeño sobre la concentración de microorganismos indicadores del queso crema tropical mantenido a temperatura ambiente. No se encontró diferencia significativa entre las concentraciones de 20 y $30 \%$ con el tratamiento control. La concentración de $40 \%$ de jugo presentó efecto inhibitorio contra $S$. aureus y levaduras, mientras que en coliformes totales, no se obtuvo efecto, probablemente relacionado con la concentración de capsaicina presente en chiles verdes. Aunque se logró disminuir la concentración de algunos microorganismos indicadores, no se alcanzó la concentración permitida aceptable establecida en la norma oficial mexicana. Debido a estos resultados, el jugo de chile jalapeño puede ser empleado como un conservador natural que ayude a disminuir el deterioro de productos de buena calidad microbiológica, lo que puede proporcionar una mayor vida de anaquel.

\section{References:}

1. Abdullah, Z., Badjah, Y., Abdelaty, M. \& Abdel, A. (2011). Determination of capsaicin and dihydrocapsaicin in capsicum fruit samples using High Performance Liquid Chromatography. Molecules. 16:8919-8929.

2. Acero-Ortega, C., Dorantes-Álvarez, L., Jaramillo-Flores, M., Hernández-Sánchez, H. \& López- Malo, A. (2003). Effect of Chili (Capsicum annuum L.) extracts and derived compounds on growth of Erwinia carotovora subsp. carotovora (Jones) Bergey, Harrison, Breed, Hammer and Huntoon. Revista Mexicana de Fitopatología. 21(2):233237.

3. Agarwal, P., Das, C., Dias, O. \& Shanbhag, T. (2017). Antimicrobial property of capsaicin. International Research Journal of Biological Sciences. 6(7):7-11.

4. Ameya, G., Aklilu, A., Bisrat, N., Nassir, M. \& Negash, A. (2018). In vitro antimicrobial activity of fermented spices and Capsicum frutescens against multi drug resistance clinical isolate and standard reference bacteria. Afr. J. Cln. Exper. Microbiol. 19(1):9-17.

5. Bacon, K., Boyer, R., Denbow, C., O’Keefe, S., Neilson, A. \& Williams, R. (2016). Antibacterial activity of jalapeño pepper (Capsicum annuum var. annuum) extract fractions against select foodborne pathogens. Food Sci Nutr. 5:730-738.

6. Barba-Macías, E., Rangel-Mendoza, J. \& Ramos-Reyes, R. (2006). Clasificación de los humedales de Tabasco mediante sistemas de información geográfica. Universidad y Ciencia, Trópico Húmedo. 22(2):101-110. 
7. Cardozo, M., Fusco, A. \& Carrasco, M. (2018). Microbiota levaduriforme en quesos artesanales de Corrientes, Argentina. Revista Argentina de Microbiología. 50(2):165-172.

8. Cerón-Carrillo, T., Munguía-Pérez, R., García, S. \& SantiestebanLópez, N. (2014). Actividad antimicrobiana de extractos de diferentes especies de chile (capsicum). Revista Iberoamericana de Ciencias. 1(2):213-221.

9. Cerón, G., Santiesteban- López, N. \& Acle, R. (2016). Combinación de dos extractos de Capsicum: composición y actividad antimicrobiana. CIBA Revista Iberoamericana de las Ciencias Biológicas y Agropecuarias. 5(10).

10. Cervantes-García, E., García-González, R. \& Salazar-Schettino, P. (2014). Características generales del Staphylococcus aureus. Rev Latinoam Patol Clin Med Lab. 61(1):28-40.

11. Colivet, J., Belloso, G. \& Hurtado, E. (2006). Comparación del efecto inhibidor de extractos de ají dulce (Capsicum chinense) sobre el crecimiento de Escherichia coli y Bacillus sp. SABER. Revista Multidisciplinaria del Consejo de Investigación de la Universidad de Oriente. 18(2):168-173.

12. Corona, A. \& Jiménez R. (2004). Comparación de dos métodos de siembra para el recuento de microorganismos en muestras con alta concentración microbiana. Revista de la Facultad de Ingeniería Química. (40):3-7.

13. Felicetti, T., Cannalire, R., Burali, M., Massari, S., Manfroni, G., Barreca, M., Tabarrini, O., Schindler, B., Sabatini, S., Kaatz G. \& Cecchetti, V. (2017). Searching for novel inhibitors of the S. aureus nora efflux pump: synthesis and biological evaluation of the 3-Phenyl1,4-benzothiazine analogues. Chem. Med. Chem. 12(16):1293-1302. doi: $10.1002 /$ cmdc. 201700286 .

14. García, R \& Herrera, F. (2007). Evaluación de la inhibición del crecimiento de cinco cepas bacterianas patógenas por extractos acuosos de Allium sativum, Allium fistulosum y Allium cepa: estudio preliminar in vitro. Bistua: Revista de la Facultad de Ciencias Básicas. 5(2):68-79.

15. Guzmán, C., Rodríguez-Rodríguez, V. \& Calderón-Rangel, A. (2017). Contaminantes microbiológicos en un mercado del sur de Montería: Un riesgo para la salud pública. Revista Ciencia y Agricultura. 14(2):89-97.

16. Hleba, L., Petrová, J., Kordiak, R., Kántor, A., Čuboň, J., Kluz, M., Shariati, M. \& Kačániová, M. (2015). Antibacterial activity of 
habanero chili sauces against selected pathogenic bacteria. Scientific Papers: Animal Science and Biotechnologies. 48(1):132-136.

17. Koffi-Nevry, R., Clément, K., Yesse, Z., Koussémon, M. \& Yao, G. (2012). Antibacterial activity of two bell pepper extracts: Capsicum annuum 1. and Capsicum frutescens. International Journal of Food Properties. 15:961-971.

18. Kurita, S., Kitagawa, E., Kim, C., Momose, Y. \& Iwahashi, H. (2002) Studies on the antimicrobial mechanisms of capsaicin using yeast DNA microarray. Bioscience, Biotechnology, and Biochemistry. 66(3):532-536.

19. Manjarrez, B., Hernández, S., De Jong, B., Nahed, J., De Dios, O. \& Salvatierra, E. (2007). Configuración territorial y perspectivas de ordenamiento de la ganadería bovina en los municipios de Balancán y Tenosique, Tabasco. Investigaciones Geográficas, Boletín del Instituto de Geografía. 64:90-115.

20. Mendoza, L. (2013). Propiedades fisicoquímicas y antioxidantes del chile jalapeño (Capsicum annuum var. annuum) fresco y seco. Universidad Veracruzana. Xalapa-Enríquez. pp 171.

21. Norma Mexicana NMX-FF-025-SCFI-2007. (2007). Productos alimenticios no industrializados para consumo humano - chile fresco (Capsicum spp). Especificaciones.

22. Norma Oficial Mexicana, NOM-121-SSA1-1994. Bienes y servicios. Quesos: frescos, madurados y procesados. Especificaciones sanitarias.

23. Omolo, M., Wong, Z., Mergen, A., Hastings, J., Le, N., Reiland, H., Case, K. \& Baumler, D. (2014). Antimicrobial properties of chili peppers. J Infect Dis Ther. 2(4):1-8.

24. Orberá, T. (2004). Acción perjudicial de las levaduras sobre los alimentos. Revista Cubana de Salud Pública, 30(3).

25. Pastrana-Puche, Y., De Paula, C. \& Gallo-García, L. (2017). Evaluación de sustancias antimicrobianas naturales en la conservación de avena sinuana. Corpoica Cienc Tecnol Agropecuaria. 18(2):321334.

26. Ramírez-López, C. \& Vélez-Ruiz, J. (2012). Quesos frescos: propiedades, métodos de determinación y factores que afectan su calidad. Temas Selectos de Ingeniería en Alimentos. 6(2):131-148.

27. Robles, P. \& Chalini, J. (2017). Conservadores que inhiben el crecimiento microbiano en la elaboración de alimentos procesados. Humanidades, Tecnología y Ciencia, Del Instituto Politécnico Nacional. 10(17):1-7.

28. Rodríguez, E. (2011). Uso de agentes antimicrobianos naturales en la conservación de frutas y hortalizas. Ra Ximhai. 7(1):153-170. 
29. Rodríguez, J., Borras, L., Pulido, M., \& Garcia, D. (2015). Calidad microbiológica en quesos frescos artesanales distribuidos en plazas de mercado de Tunja, Colombia. Revista Cubana de Higiene y Epidemiología. 53(3).

30. Romero-Castillo, P., Leyva-Ruelas, G., Cruz-Castillo, J. \& SantosMoreno, A. (2009). Evaluación de la calidad sanitaria de quesos crema tropical mexicano de la región de Tonalá, Chiapas. Revista Mexicana de Ingeniería Química. 8(1):111-119.

31. Sáenz, A. \& D'Alolio, O. (2007). Identificación de pérdidas poscosecha de chile jalapeño (Capsicum annuum L. cultivar mitla) para uso agroindustrial. Consejo Nacional de Producción. San José (Costa Rica). pp 5.

32. Sandhya, M. \& Vijayakumar, N. (2016). Comparative study on antimicrobial activity of eight capsicum species - A novel therapeutic compound. Indian Journal of Research. 5(6):103-107.

33. Soto, Z., Pérez, L. \& Estrada, D. (2016). Bacterias causantes de enfermedades transmitidas por alimentos: una mirada en Colombia. Revista Científica Salud Uninorte. 32(1). DOI: http://dx.doi.org/10.14482/sun.32.1.8598.

34. Vásquez, V., Salhuana, J., Jiménez, L., \& Abanto, L. (2018). Evaluación de la calidad bacteriológica de quesos frescos en Cajamarca. Ecología Aplicada. 17(1):45-51.

35. Villegas, A., Santos, A. \& Cervantes, F. (2016). Los quesos mexicanos tradicionales. Universidad Autónoma Chapingo: Juan Pablos Editor, 1a. edición. México. pp. 195. 